\title{
REAKTUALISASI GARAP MUSIK KESENIAN \\ PENTHUL MELIKAN DI DUSUN MELIKAN DESA TEMPURAN \\ KABUPATEN NGAWI
}

\author{
Wahyu Paramita Jati dan Suyoto \\ Program Studi Karawitan, Fakultas Seni Pertunjukan \\ Institut Seni Indonesia \\ wahyuparamita96@gmail.com
}

\begin{abstract}
Abstrak
“ Reaktualisasi Garap Musik Kesenian Penthul Melikan Di Dusun Melikan Desa Tempuran Kabupaten Ngawi" pada dasarnya membahas garap musik kesenian Penthul Melikan Kabupaten Ngawi setelah mengalami perubahan yang kemudian disebut Reaktualisasi.

Inti permasalahan yang diungkap dalam penelitian ini adalah (1) Bagaimana bentuk garap musik pada kesenian Penthul Melikan di Dusun Melikan, Desa Tempuran, Kecamatan Paron Kabupaten Ngawi (2) Faktor penyebab perubahan musik pada kesenian Penthul Melikan di Dusun Melikan, Desa Tempuran, Kecamatan Paron Kabupaten Ngawi. Penelitian ini adalah penelitian kualitatif, metode yang digunakan adalah metode penelitian kualitatif, meliputi observasi, pengumpulan data, dan analisis data.

Penelitian ini menggunakan teori, konsep-konsep, dan pemikiran dari beberapa tokoh. Landasan konseptual Reaktualisasi menurut Geriya bahwa adanya proses transformasi dalam perubahan bentuk dan fungsi namun tetap dalam esensi spesiesnya. Teori kreativitas diungkapkan Munandar, bahwa manusia yang memiliki kreativitas sehingga mampu untuk menciptakan sesuatu dari tidak ada menjadi ada, dari yang sudah ada menjadi lebih baru lagi. Penelitian ini juga menggunakan teori perubahan yang ditawarkan Boskoff ketika mengupas tentang perubahan atau pembaharuan, yang pada dasarnya disebabkan oleh dua faktor, yaitu faktor internal dan faktor eksternal. Teori garap Supanggah, bahwasanya Reaktualisasi musik pada kesenian Penthul Melikan terdapat beberapa unsur garap meliputi; (1) materi garap, (2) penggarap, (3) sarana garap, (4) perabot garap, (5) penentu garap, dan (6) pertimbangan garap.

Dari hasil penelitian disimpulkan bahwa ada pengaruh positif terhadap kesenian Penthul Melikan setelah mengalami reaktualisasi, adanya perubahan garap dan bentuk baru pada kesenian Penthul Melikan yang kemudian dinamakan Ganongan Melikan, membuat kesenian Penthul Melikan dengan bentuk dan garap yang lama kembali dikenal masyarakat dan semakin berkembang.
\end{abstract}

Kata kunci: Reaktualisasi, Garap, Kesenian Penthul Melikan.

\begin{abstract}
"A reactualisation of the musical style of Penthul Melikan in Dusun Melikan, Desa Tempuran, Ngawi Regency" is a discussion of the musical style found in the Penthul Melikan performance which has changed through a process Geriya terms "reactualisation". This research explores the following issues: 1) What is the musical style of Penthul Melikan in Dusun Melikan, Desa Tempuran, located within the Paron sub-district of the Ngawi Regency, as well as 2) the factors that changed the music of this art form. This qualitative research uses qualitiative methods including observation, data collection and data analysis.
\end{abstract}

This research employs the theories, concepts and ideas of several figures. Geriya's Reactualisation involves, 
as its foundation, a transformation within the art form in formal and functional qualities while nonetheless retaining the essence of its species. Munandar's theory of creativity explores the human ability to create something from nothing, and the new from the currently existing. Change and renewal are discussed through Boskoff's theory of change which focuses on internal and external factors. Supanggah's theory of garap, which discusses the musical materials and tools at the disposal of the musicians is also relevant to studying the reactualisation of Penthul Melikan.

The findings suggest that reactualisation has had a positive effect on Penthul Melikan, which later became known as Ganongan Melikan. This has allowed the former style of Penthul Melikan to re-enter its community and develop further.

Keywords: Reactualisation, Garap, Penthul Melikan

\section{Pengantar}

Daerah Ngawi terdapat berbagai jenis kesenian rakyat yang memiliki nilai sosial cukup tinggi, antara lain: Orèk-orèk, Gaplé, Keduk Bèji, Klanthung, Tari Bedhaya Srigati, dan Penthul Melikan. Unsur-unsur gerak tari dan alunan musikal yang unik menjadi ciri khas tersendiri bagi kesenian Penthul Melikan.

Penthul Melikan adalah jenis kesenian tari rakyat berasal dari Dusun Melikan, Desa Tempuran, Kecamatan Paron, Kabupaten Ngawi. Oleh karena berasal dari dusun Melikan, kemudian masyarakat menyebutnya Penthul Melikan. Kesenian ini menggambarkan rasa syukur dan kegembiraan masyarakat Melikan atas keberhasilan membangun jembatan yang menghubungkan antara Desa Tempuran bagian barat dan timur, dan membangun Madrasah Tarbiyatun Wardha sebagai sarana Pendidikan anak-anak, kemudian membuat suatu tontonan yang menarik, meriah, dan lucu. Properti yang menjadi andalannya adalah topeng. Topeng yang digunakan itu kemudian disebut penthul, yang bahannya terbuat dari kayu dadap. Topeng yang dikenakan memiliki karakter yang berbeda-beda, sesuai dengan watak manusia (Solikin, wawancara 25 Januari 2018).

Alat musik pada kesenian Penthul Melikan menggunakan sebagian perangkat gamelan Jawa yang pola tabuhannya sepertinya terpengaruh musik Reog Ponorogo. Seiring dengan perkembangan zaman, kesenian daerah mulai ditinggalkan masyarakat seperti yang terjadi pada kesenian Penthul Melikan. Pada tahun 1980-an kesenian Penthul Melikan tidak dipentaskan lagi, karena masyarakat merasa jenuh dengan garap musik dan tarinnya yang membosankan.

Pada tahun 2012, Imam Joko Sulistyo seniman asal Ngawi berinisiasi menggarap kembali musik pada kesenian Penthul Melikan. Penthul Melikan yang sebelumnya jumlah personil dan alat musik sangat minimalis (bedhug, kendhang, dan dua pencon bonang) kemudian ada penambahan instrumen (kendhang, bonang barung, saron, demung, kempul, dan vokal), sehingga garap musiknya menjadi lebih variatif. Kemudian kesenian ini ada yang menyebutnya Ganongan Melikan.

Hal yang cukup menarik dari kesenian Penthul Melikan dan Ganongan Melikan adalah keduanya berjalan dengan baik tanpa ada perselisihan yang berarti, baik Penthul Melikan yang lama maupun Penthul Melikan yang baru atau yang telah direaktualisasi. Maka reaktualisasi musik pada kesenian Penthul Melikan menjadi sangat menarik dan penting untuk dikaji, karena terdapat beberapa permasalahan yang perlu dijelaskan. 
Berdasarkan latar belakang tersebut, maka masalah yang ingin digali diantaranya bentuk dan garap musik pada kesenian Penthul Melikan di Dusun Melikan, Desa Tempuran, Kecamatan Paron Kabupaten Ngawi dan faktor perubahan garap musik pada kesenian Penthul Melikan.

\section{Bentuk Pertunjukan Kesenian Penthul Me- likan}

Tempat pertunjukan kesenian Penthul Melikan dilaksanakan di tempat terbuka, para pemain berada di titik pusat dan tidak terikat pada tempat khusus seperti lapangan, halaman rumah, di jalan dan sebagainya. Tempat pertunjukan harus luas sehingga gerak-gerak penari dapat berkembang dan mengingat jumlah penari cukup banyak. Penonton berada di sekeliling arena yang digunakan untuk pertunjukan tersebut. Letak penari tergantung tempat pada pertunjukan kesenian Penthul Melikan.

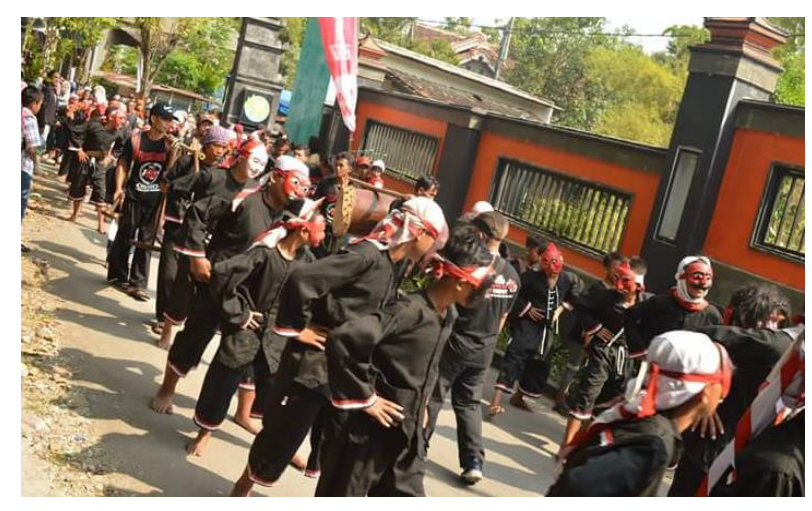

Gambar 6. Pertunjukan Penthul Melikan di jalan (Dokumen: Solikin (2017)

Kesenian Penthul Melikan biasanya dipentaskan dalam acara hari jadi Kabupaten Ngawi, karnaval desa, hari jadi Republik Indonesia, takbir keliling pada saat bulan ramadhan dan acara-acara even lainnya.

\section{Awal mula Kesenian Penthul Melikan}

Kesenian Penthul Melikan merupakan tari rakyat yang berasal dari Dusun Melikan, Desa Tempuran, Kecamatan Paron Kabupaten Ngawi. Penthul Melikan berasal dari kata Penthul, pentholan, dan melikan. Penthul berarti dipenke nuthul (makan), pentholan (pimpinan) yaitu kita harus mematuhi pemimpin, dan melikan adalah dusun dimana tari penthul itu ada dan diciptakan (Solikin, wawancara 4 April 2018).

Penthul Melikan berarti tari penthul yang menggambarkan kehidupam manusia yang mengutamakan nuthul (makan) karena manusia hidup perlu makan dan beraktivitas dalam bentuk apapun. Penthul Melikan melambangkan kehidupan manusia terutama tingkah laku dan perbuatan yang baik. Penuntun hidup yang dilambangkan pada gerak-gerak tari Penthul Melikan yang terdiri dari tujuh gerakan pokok serta karakteristik manusia yang berbeda-beda yang dilambangkan pada bentuk penthul (topeng) yang digunakan dalam tari Penthul Melikan.

Pencipta tari Penthul Melikan adalah Bapak Munadjah, beliau lahir di Ponorogo tahun 1901. Keluarga besar Bapak Munadjah berasal dari dusun Melikan Desa Tempuran Kecamatan Paron Kabupaten Ngawi. Perang kemerdekaan telah membuat keluarga pencipta terpisah, orang tua pencipta beserta keluarga sampai ke Ponorogo. Setelah terjadi perang, warga Melikan senang tirakat, sehingga tidak heran jika di dusun Melikan banyak orang yang terkenal sebagai orang pintar. Masjid atau surau banyak sekali terdapat di dusun Melikan. Dusun Melikan menjadi pusat kegiatan Islam bagi desa Tempuran. Melihat keadaan yang semakin maju dalam hal beragama, maka aparat desa Melikan menganggap penting dilaksanakan pembangunan sekolah yaitu sebuah gedung Madrasah Tarbiyatun Wardha. Sarana pendidikan formal tersebut sangat diperlukan untuk membantu kemajuan pendidikan anak-anak, selain pendidikan ilmu agama yang diperoleh dari guru-guru mengaji yang dilaksanakan di masjid-masjid. Selain sekolah, jembatan yang menghubungkan antara desa Tempuran bagian barat dan timur segera dilaksanakan pembangunannya.

Pada tahun 1952 pembangunan gedung sekolah dan jembatan telah selesai. Hal itu merupakan kegembiraan tersendiri bagi penduduk Tempuran khususnya masyarakat 
Melikan. Sebagai ungkapan rasa syukur dan gembira kepada Allah, para pemuka agama (salah satunya bapak Munadjah), tokoh masyarakat serta pamong desa Melikan mencoba menciptakan kesenian yang sifatnya meriah dan lucu. Kesenian tersebut akan dipentaskan pada waktu perayaan peresmian Madrasah dan jembatan yang dipimpin oleh Bapak Munadjah sekaligus sebagai pencipta gerak tari Penthul Melikan.

Situasi masyarakat pada waktu kesenian Penthul Melikan itu diciptakan masih bercorak tradisional Jawa yang kuat, dengan tanda- tandanya yaitu kehidupan masyarakat berorientasi kepada pemuka masyarakat, memegang tradisi yang telah ada dan kehidupan masyarakatnya masih bersifat kerakyatan. Gotong royong dan suka menolong dipengaruhi oleh sistem mata pencaharian yang sebagian besar bertani. Ketika itu hasil pertanian cukup melimpah, namun keadaan ekonomi masyarakat masih sederhana, karena negara RI pada waktu itu baru saja lepas dari penjajah. Sarana transportasi masih sangat sederhana. Hal inilah yang mempengaruhi sifat kesenian Penthul Melikan yang diciptakan sangat sederhana pula. Selain sifatnya yang sederhana, kesenian Penthul Melikan merupakan kesenian yang bernuansa islam. Sebagai cirinya yaitu terdapat pada syair-syair lagu dan fungsinya. Hal itu karena dipengaruhi oleh situasi masyarakat yang beragama islam dan taat menjalankannya. Sebagai seni turun temurun sampai sekarang tentunya tari Penthul Melikan perlu diketahui siapa penciptanya dan siapa penerusnya.

1. Munadjah (1952) sekaligus pemimpin. Pada masa kepemimpinan beliau iringan masih mempergunakan seng, drum (tong) dan kentongan, syair lagunya hanya syair kemerdekaan.

2. Sahid dan Harjo Dimono (1964) pada masa kepemimpinan Ia Kesenian Penthul Melikan mengalami perkembangan syair lagu dan musiknya mempergunakan alat musik gamelan Jawa yaitu bonang, kendhang gedhe dan jedor.
3. Warsono (1982) pada masa kepemimpinan beliau ada pengembangan hiasan pakaian, tempat pertunjukan, waktu pertunjukan, desain lantai.

Pada masa pimpinan Marsono, dengan berkembangnya zaman kesenian ini semakin vakum tidak dipentaskan lagi. Karena pengaruh modernisasi masyarakat lebih memilih kesenian yang terlihat lebih variatif daripada monoton seperti kesenian rakyat. Melihat kondisi tersebut, seorang seniman Ngawi yang bernama Imam Joko Sulistyo bergerak hatinya untuk menggarap ulang kesenian Penthul Melikan agar tidak terlihat monoton dan mengikuti perkembangan jaman.

\section{Kronologi kesenian Penthul Melikan menja- di Ganongan Melikan}

Tari Ganongan Melikan adalah kesenian yang berasal dari Ngawi. Tari Ganongan Melikan diciptakan oleh seorang seniman bernama Imam Joko Sulistyo. Kesenian Ganongan Melikan adalah bentuk kesenian yang sudah ada kemudian digarap ulang. Garap musik dan tari Ganongan Melikan merupakan reinterpretasi dari kesenian Penthul Melikan yang berasal dari dusun Melikan Desa Tempuran Kecamatan Paron Kabupaten Ngawi. Ganongan Melikan hanyalah sebutan dari Imam, pada dasarnya kesenian ini adalah kesenian Penthul Melikan yang bentuk musik dan tarinya digarap ulang.

Tahun 2012 Imam Joko Sulistyo meminta ijin kepada Solikin (keturunan Bapak Munadjah) sekaligus pemimpin kesenian Penthul Melikan untuk mereaktualisasi kesenian Penthul Melikan. Imam Joko sulistyo tidak meninggalkan ciri khas yang ada pada kesenian Penthul Melikan, karenan Penthul Melikan dijadikan pijakan untuk membuat karya barunya. Imam Joko Sulistyo mengubah musik agar tidak terlihat monoton dengan menambah sebagian alat musik karawitan (Kendang, bonang barung, saron, demung, kempul, 
kenong, dan vokal), gerak, dan pola lantai. Imam Joko Sulistyo memberi nama kesenian ini dengan "Ganongan Melikan".

Imam Joko Sulistyo mengganti nama Penthul Melikan dengan Ganongan Melikan karena mengingat pencipta awal kesenian ini berasal dari Ponorogo, dan kesenian Penthul Melikan merupakan kesenian yang berdiri sendiri jadi Imam Joko Suliatyo harus mengubah nama agar tidak sama (Solikin, wawancara 27 April 2018). Setelah garap musik tari yang dibuat Imam Joko Sulistyo jadi, hal ini menjadi dampak positif untuk kesenian Penthul Melikan yang dahulu hampir punah sekarang semakin berkembang setelah melihat garap musik tari Ganongan Melikan yang digarapoleh Imam Joko Sulistyo. Meskipun tidak meninggalkan ciri khas dari garap yang dulu, garap pada musik Ganongan Melikan, terlihat lebih variatif sehingga lebih menarik.

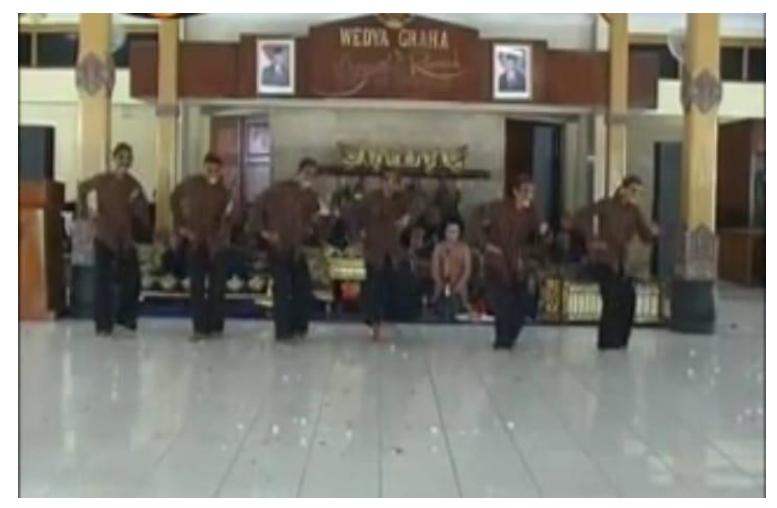

Gambar 9. Tari Ganongan Melikan

(dokumen: Imam Joko Sulistyo, 2012)

Kesenian Ganongan Melikan termasuk kesenian rakyat karena gerak, iringan, rias, maupun tema nya sederhana. Kesenian tari Ganongan Melikan selain untuk hiburan, dan pentas HUT Kabupaten Ngawi sekarang dijadikan bahan untuk mata pelajaran. Di beberapa sekolah di Kabupaten Ngawi menggunakan tari Ganongan Melikan sebagai mata pelajaran praktek seni budaya. Pada tahun 2014 kesenian Ganongan Melikan pernah ditarikan oleh 4000 penari anak-anak di alun-alun Ngawi dalam rangka hari jadi Kabupaten Ngawi.

\section{Kesenian Penthul Melikan pasca Reaktual- isasi}

Kesenian Penthul Melikan mengalami reaktualisasi, dengan digarap kembali oleh Imam Joko Sulistyo pada tahun 2012 yang kemudian dinamakan Ganongan Melikan. Hal tersebut, berdampak positif terhadap bentuk kesenian Penthul Melikan yang dulu. Pada tahun 2012 Imam membuat rekaman kesenian Ganongan Melikan di Pendhapa Kabupaten Ngawi. Setelah rekaman video atau kaset tersebut sudah jadi dan dipublikasikan, masyarakat menganggap kesenian tersebut adalah kesenian Penthul Melikan. Hal ini membuat kesenian Penthul Melikan kembali di ingat masyarakat, bahwa bentuk dan garap pada kesenian Penthul Melikan yang asli masih ada.

Mendengar hal tersebut, Solikin warga dari Dusun Melikan, membangun kembali kesenian Penthul Melikan di Dusun Melikan Desa Tempuran Kecamatan Paron Kabupaten Ngawi dengan membentuk susunan organisasi yang diketuai oleh Solikin. Pada tahun 2015 Solikin menjadi ketua kelompok kesenian Penthul Melikan. bertambah tahun anggota kesenian Penthul Melikan bertambah. Kesenian Penthul Melikan kembali berkembang dan dikenal masyarakat. tidak hanya dikenal masyarakat, bahkan kesenian Penthul Melikan mengisi berbagai acara seperti, karnaval INBOX SCTV yang berada di alun-alun Ngawi, pentas di Korea yang diwakilkan oleh anak SMP Negeri 2 Ngawi, dipentaskan di Taman Budaya Surabaya, karnawal di Ngawi, Nganjuk, Solo dan di Yogjakarta.

\section{Faktor Pendukung Reaktualisasi}

\section{Faktor Internal}

Faktor internal yang menyebabkan musik tari Penthul Melikan Kabupaten Ngawi digarap ulang yang dimaksudkan di sini adalah faktor yang berasal dari dalam seperti:

\section{a. Faktor Kejenuhan}

Kesenian rakyat hidup secara turun tem- 
urun dalam suatu kelompok masyarakat. Kesenian rakyat tidak bisa lepas dari peran seniman. Jiwa seniman yang melekat membuatnya antusias dalam mengembangkan suatu kesenian. Merasa bosan dengan garap musik Penthul Melikan yang terlihat sangat sederhana, Ia mencoba menggarap ulang musik kesenian tari Penthul Melikan agar di era modern seperti sekarang, kesenian rakyat akan tetap tumbuh dan berkembang dengan mengalami perubahan-perubahan dalam bentuk kesenian tersebut.

\section{b. Kreativitas Seniman}

Reaktualisasi musik pada kesenian Penthul Melikan dipelopori oleh seniman Ngawi yang bernama Imam Joko Sulistyo, seorang penari sekaligus koreografer. Perubahan pada garap musik Penthul Melikan yang awal mulanya sangat sederhana dan menjadi lebih variatif digarap tepatnya pada tahun 2012. Pada tahun 1952-an model kesenian tari Penthul Melikan sangat sederhana, gerak tari dan iringan musik sangat sederhana, penyajiannya juga hanya diulang-ulang. Model tersebut tidak lagi diminati oleh masyarakat, yang mengakibatkan kesenian ini vakum mulai tahun 1980-an.

Pada tahun 2012, Imam Joko Sulistyo menggarap ulang bentuk musik dan tari Penthul Melikan. Imam Joko Sulistyo menambahkan beberapa alat musik dengan gamelan lebih lengkap seperti Kendhang, Saron, Demung, Bonang, Kempul, Gong, dan vokal, dan menambah gerak tari. Di samping melakukan penambahan alat musik, Imam juga melakukan pengembangan dalam hal variasi garap musik sehingga garap musik Penthul Melikan lebih variatif dan tidak terkesan monoton.

\section{c. Fasilitas}

Fasilitas juga faktor yang penting sebagai menunjang perkumpulan seniman untuk menggarap ulang garap musik pada tari Penthul Melikan. Imam Joko Sulistyo seorang pemimpin Sanggar kesenian yang bernama Soeryo budoyo yang beralamat di Jln. Kartini No. 03, Ngawi. Tempat latihan dan seperangkat gamelan berlaras slèndro dan pèlog sudah disediakan oleh pemimpin sanggar
Soeryo Budoyo tersebut. Tanpa adanya fasilitas- fasilitas tersebut, para seniman tidak akan dapat melakukan kegiatan latihan.

\section{Faktor Eksternal}

Faktor yang mempengaruhi terjadinya reaktualisasi musik Penthul Melikan Kabupaten Ngawi diantaranya adalah pengaruh dari luar. Masuknya pengaruh-pengaruh dari luar dalam suatu kesenian mampu mengubah dan memberi motivasi dalam perubahan dan perkembagan suatu kesenian rakyat. Baik disengaja maupun tidak disengaja, pengaruh dari luar dapat memberikan dorongan agar kesenian rakyat dapat terus berkembang tanpa menghilangkan unsur-unsur pokok dalam kesenian tersebut. Adapun pengaruh luar yang mempengaruhi terjadinya reaktualisasi musik Penthul Melikan sebagai berikut.

\section{a. Kemajuan Teknologi Informasi dan Ko- munikasi (TIK)}

Arus globalisasi membawa pengaruh yang cukup kuat terhadap kehidupan masyarakat secara global, hal ini karena teknologi informas dan komunikasi yang menjadi media interaksi masyarakat saat ini. Televisi, radio, internet, surat kabar, telepon/handphone, telah menjadi sarana komunikasi bagi masyarakat. Tidak heran jika saat ini kita mampu memperoleh informasi atau berita tentang kehidupan masyarakat luar melalui media-media informasi tersebut. Media komunikasi modern membuat setiap warga betah tinggal di rumah. Warga dapat memilih acara dari selurug dunia yang mereka sukai dengan mudah, sehingga membuat daya apresiasi warga terhadap pentas-pentas kesenian dan bentuk musik berbagai daerah.

Masyarakat Ngawi merupakan bagian dari masyarakat yang merasakan perkembangan teknologi tersebut. Internet juga sebagai salah satu bentuk teknologi informasi yang paling mudah diakses, dan terjangkau. Hal ini bisa dilihat dari kebanyakan masyarakat Ngawi sekarang menggunakan in- 
ternet, bahkan warga yang tinggal di pedesaan sekalipun. Internet bahkan menjadi salah satu kebutuhan dan gaya hidup masyarakat. Dengan internet mereka bisa mengakses berbagai media sosial, salah satunya media sosial Youtube. Dengan Youtube masyarakat bisa melihat perkembangan bidang apapun termasuk kesenian bahkan kehidupan budaya masyarakat luar.

Adanya berbagai bentuk musik dan kesenian yang diunggah dimedia sosial, membuat semakin banyak referensi bagi para seniman. Adanya referensi menjadikan pola berfikir seniman semakin luas. Hal tersebut mendorong seniman Ngawi untuk membuat karya dalam bentuk baru maupun reaktualisasi bentuk kesenian yang sudah ada seperti kesenian Penthul Melikan. Para seniman mereaktualisi kesenian agar tidak tertinggal dengan kesenian daerah lain. Hal ini membuktikan bahwa media sosial, perkembangan teknologi dan informasi menjadi faktor terjadinya reaktualisasi musik kesenian Penthul Melikan Kabupaten Ngawi.

\section{b. Pengaruh Kebudayaan lain}

Di era globalisasi seperti sekarang tidak menutup kemungkinan bagi masyarakat untuk berinteraksi dengan daerah lain. Interaksi dengan daerah lain menimbulkan pengaruh dari masyarakat daerah tersebut. Dengan demikian akan timbul suatu nilai-nilai sosial budaya yang baru sebagai akibat asimilasi atau akulturasi kedua kebudayaan daerah. Akulturasi adalah suatu kebudayaan tertentu yang dihadapkan dengan unsur-unsur kebudayaan asing, yang lambat laun unsur kebudayaan asing tersebut melebur atau menyatu ke dalam kebudayaan sendiri (asli). Dengan melihat bentuk-bentuk kesenian daerah lain, mengakibatkan seniman ingin membentuk kesenian daerah sendiri agar seperti daerah lain, walaupun tetap menggunakan ciri khas kesenian daerah Ngawi sendiri (Sri, wawancara 9 Juni 2018).

\section{c. Faktor Pendidikan}

Perkembangan pendidikan masyarakat Kabupaten Ngawi saat ini mengalami kemajuan semakin membaik. Hal tersebut dapat dilihat dari banyaknya anak-anak daerah Ngawi yang mendapatkan pendidikan mulai dari bangku sekolah dasar sampai perguruan tinggi. Semakin tinggi tingkat pendidikan, maka pemikiran masyarakat setempat juga semakin terbuka. Selain itu, lewat pendidikan masyarakat terbiasa untuk berfikir secara ilmiah, rasional, dan objektik.

Dengan pendidikan, seseorang memiliki pengetahuan formal maupun non formal. Pengetahuan tersebut akan menimbulkan cara pandang yang berbeda-beda dalam menghadapi sebuah permasalahan di dalam masyarakat. Karena hal tersebut, masyarakat Ngawi mengiginkan kesenian daerah harus dikembangkan salah satunya adalah kesenian Penthul Melikan. Agar kesenian Penthul Melikan tetap berkembang pada jaman modern seperti sekarang.

\section{Deskripsi Musikal Penthul Melikan}

\section{Bentuk musik}

Bentuk musik pada kesenian Penthul Melikan tidak memiliki struktur seperti bentuk musik dalam gending-gending tradisi Jawa. Tidak menunjukkan pula instrumen yang membentuk struktur seperti kethuk, kempul, kenong, dan Gong. Alat musik pada kesenian Penthul Melikan berupa bedhug, kendhang, dua pencon bonang, dan jér. Tidak ada aturan khusus harus suwuk dan harus melambat atau mencepat, tetapi semua sama, hanya berulang-ulang. Perubahan-perubahan gerak penari, pola gerak, ditandai oleh bunyi tiupan peluit.

\section{Garap musik}

Iringan musik pada perkembangan Penthul Melikan merupa kan unsur yang penting da- 
lam suatu pertunjukan tari, tugas iringan adalah mempertegas maksud dan memberikan rangsangan estetis (keindahan) pada penarinya. Pada iringan musik kesenian Penthul Melikan ada beberapa alat musik yang digunakan, yaitu sebagai berikut.

\section{Peluit}

Tiupan peluit oleh komandan penari sebagai tanda awal lagu untuk mengiringi kesenian Penthul Melikan, berdasarkan kesepakatan antara penari dan pengiring musik. pola kendhangan dan tari pada kesenian Penthul Melikan akan berganti pola, tergantung komandan penari meniup peluit tersebut.

\section{Bonang}

Dalam iringan kesenian Penthul Melikan menggunakan dua pencon bonang berlaras sléndro yang nadanya 5 dan 6 . Setelah peluit berbunyi, pola tabuhan pada bonang adalah

4565. 565. . Iringan pokok dalam kesenian Penthul Melikan hanya menggunakan || 565. 565. . | dari awal sampai akhir.

\section{Kendhang}

Kendhang dalam iringan musik berfungsi sebagai pemimpin. Dalam kesenian Penthul Melikan, kendhang digunakan sebagai penanda untuk berubah pola satu ke pola berikutnya dengan tanda singget setelah peluit dibunyikan. Berikut adalah pola kendhang yang digunakan untuk mengiringi musik kesenian Penthul Melikan.

$$
\begin{aligned}
& \text { 1) Sekaran }\|\underline{.6 . t} . .6 . .6 . t .6 . .\| \\
& \text { singgetan }\|.6 . t .6 . . . d b d \cdot \overline{. b \rho \ell p t}\|
\end{aligned}
$$

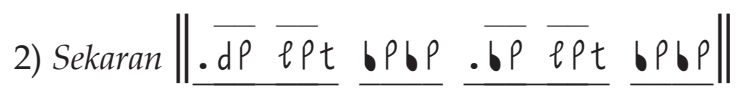

$$
\begin{aligned}
& \text { Singgetan } \| \cdot \overline{d P} \overline{l \rho t} \text { bPbP } . d b d . \overline{.6 P} \overline{l P t} \|
\end{aligned}
$$
3) Sekaran \|.t.b.d.b.t.b. $. d \cdot t \quad \|$
Singgetan $\|. t . b . d . b . d b d . \overline{b P l}\|$
4) Sekaran $\|$. .t.P.P.P. .P.b .6...
5) Sekaran $\|$. .t.P.P.P.P.b. ...

\section{Bedhug}

Bedhug adalah jenis ricikan mirip kendang tetapi berukuran sangat besar. Ricikan ini menghasilkan suara yang sangat berat. Dalam musik kesenian Penthul Melikan Bedhug digunakan untuk penguat rasa sèlèh pada lagu.

Jèr

Jèr adalah alat musik terbuat dari lempengan besi yang ditabuh dengan cara dipukul. Masyarakat Melikan membuat Jèr dengan kreativitas mereka sendiri. Sebutan "jèr" disebabkan oleh bunyi yang ditimbulkan oleh benda tersebut. Jèr sebagai pelengkap agar musik terlihat meriah. Alat musik Jèr biasanya dibawa oleh dua orang dengan cara di pikul dan orang yang belakang bagian yang memainkannya. Dalam kesenian Penthul Melikan, Jèr ditabuh bersamaan dengan bedhug.

\section{Syair (cakepan) dan lagu}

Dalam kesenian Penthul Melikan terdapat syair dan lagu yang digunakan. Lagu tersebut disuarakan dengan laras pélog. Yang menyuarakan syair tersebut adalah pemain musik pada kesenian Penthul Melikan. berikut syair dan lagu yang terdapat pada kesenian Penthul Melikan:

Vokal 1:

\begin{tabular}{||lllllllll}
\hline .3 & $\overline{53}$ & $\overline{5}$ & 6 & 7 & $\overline{.7}$ & $\overline{1} 7$ & $\overline{6} 7$ & 5
\end{tabular}

Ma-ri teman- teman ma-ri-lah temanku $\begin{array}{llllllll}\overline{.5} & \overline{6} & \overline{65} & 4 & \overline{.5} & 6 & \text { i } 7\end{array}$

bersama-sama berdendang 


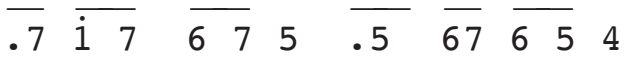

ber-den-dang-lagu sam-bil me-na-ri

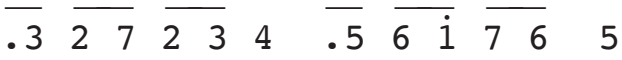

me-nari-pen-thul un-tuk-meng-hibur

vocal 1: $\left\|\begin{array}{llll}-3 & 7 & 2 & 3\end{array}\right\|$

Ha-ti bi-ngung

Vokal 2: $\|$. . ii $\quad$..77

Oo aa

Vokal 3: $\|. \overline{7 i} \overline{7 i} 7\|$

Ma ju wo

Vokal 4: $\|$\begin{tabular}{ccc|}
\hline$\overline{7}$ & $\overline{\mathrm{i}}$ & 7
\end{tabular}

Se la lu

Vokal 5: $\|\underline{.7 i} \overline{7 i} 7\|$

In saf lah

Vokal 6: $\|. \overline{7 i} \overline{7 i} 7\|$

Su dah lah

Vokal 7: $\|. \overline{7 i} \overline{7 i} 7\|$

Aku su ka

\section{Bentuk dan Garap Kesenian Ganongan Me-} likan (Reaktualisasi Penthul melikan)

\section{Bentuk Musik}

Pada dasarnya kesenian Ganongan Melikan adalah bentuk reaktualisasi dari kesenian Penthul Melikan, namun bentuk musik pada kesenian Ganongan Melikan berbeda dengan kesenian Penthul Melikan yang tidak memiliki struktur, musik dalam kesenian Ganongan Melikan lebih berstruktur, karena ada ricikan yang mendukung adanya struktur pada musik, seperti kempul. Perpindahan pola garap musik dan penari ditandai dengan adanya singgetan pada kendang, dan pada musik kesenian Ganongan Melikan memiliki bentuk seperti gangsaran dalam karawitan Jawa.

\section{Garap musik}

Penthul Melikan yang sekarang diubah menjadi Ganongan Melikan oleh Imam Joko Sulistyo menggunakan gamelan lengkap berlaras slendro yang memiliki struktur jelas yaitu gangsaran. Variasi garap pada musik tari Ganongan Melikan lebih menarik karena memiliki banyak pola pada garap musiknya, dibanding musik Penthul Melikan. Garap pada intro yang

diawali dari buka kendhang $\overline{b b} \bar{b} t t_{0}$ yang dilanjut dengan pola balungan $\overline{\overline{666}}$ $\overline{66532} \overline{\overline{666}} \quad \overline{66532} \overline{2252536}$ kemudian penari masuk dengan pola balungan $\|2356\|$ sampai posisi penari ditenggah kemudian kendhang memberi ater perpindahan iringan menjadi $\underline{6} 12 \quad 123 \quad 235 \quad 356 \quad \ldots 66 \quad \ldots 66$, peran kendhang disini sangat penting sebagai ater pada tari dan garap iringan. Gendhing yang digunakan pada iringan tari Ganongan

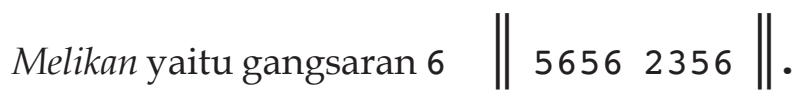

Peran kendang sangat penting sebagai ater pada tari dan garap iringan. Setiap perpindahan pola musik dan gerak tari selalu ditandai dengan kendangan sebagai pertanda peralihan gerak dan pola musik. Berikut pola kendang yang digunakan sebagai ater atau perpindahan gerak dan musik . . $\overline{d d} t \rho b$. 
Berikut deskripsi bentuk sajian musik Penthul Melikan.

a. buka Kendhang $\overline{\mathrm{d} b} \cdot \overline{\mathrm{t}} \mathrm{t} \odot$ kemudian diselehi semua instrumen dengan nada seleh 2 .

b. Nada seleh 2 yang ditabuh semua balungan kemudian di tampani dengan tabuhan bonang

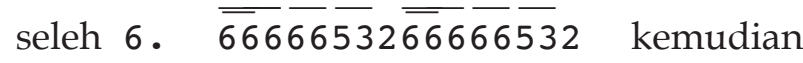
bonang $\overline{22} \overline{52} \overline{35}$ (6).

c. Demung: $\quad 2 \quad 3 \quad 3 \quad 5 \quad 6 \quad \|$ (gangsaran 6).dengan variasi pada pola

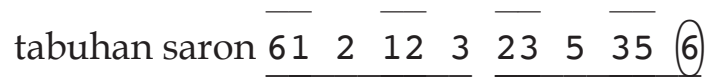

d. Pola tabuhan Kempul pada saat variasi tabuhan saron. Pola berikut ini dinamakan

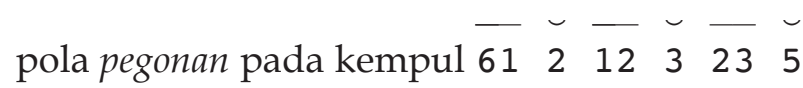

35 6. Menurut Imam, teknik kempul pegonan biasa yang digunakan pada tabuhan Reog Ponorogo. j. Masuk vokal dengan balungan $\underline{6523} \underline{6523}$

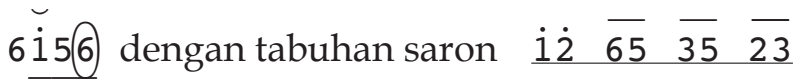
$\begin{array}{lllllllll}\overline{35} & \overline{65} & \overline{35} & \overline{33} & \overline{6 i} & \dot{2} i & \overline{6 i} & \overline{66} & \\ & & & \end{array}$ jengglengan nada 6 manut kendang.

k. $\underline{6523} \underline{6523} \underline{6 i 56}$ dengan tabuhan saron

$\begin{array}{llllllllllll}i 2 & \overline{65} & \overline{35} & \overline{23} & \overline{35} & \overline{65} & \overline{35} & \overline{33} & \overline{6 i} & \overline{2} & \overline{1} & \overline{66}\end{array}$ kemudian jengglengan nada 6 manut kendang.

1. Gangsaran $6 \quad \| \begin{array}{llll}2 & 3 & 5 & 6\end{array}$

m. Klotekan

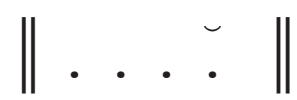

n. Klotekan pola 1: $\|x \times x \times\|$

o. Klotekan pola 2: $\| \mathrm{XX}$ XXXXX

p. Klotekan pola 3: $\| \mathrm{XXXXXX \|}$

q. Klotekan pola 4: $\|\mathrm{X} \times \mathrm{X} \times \mathrm{XX}\|$

r. Gangsaran 6. $\quad \|$\begin{tabular}{lllll||}
2 & 3 & 5 & 6
\end{tabular}

s. Vokal bawa atau nembang

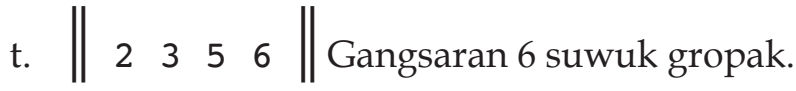

1. Notasi Kendhang dan urutan sajian garap

Buka : $\quad \overline{\mathrm{d} b} \cdot \overline{\mathrm{t}} \mathrm{t}$

Pola 1: $\|$ tbtb tbtb tbtb dbtb\| 
peralihan ke pola 2

\section{$\rightarrow \underline{t b t b}$ tbtb dtdt $\underline{\rho b \rho t}$}

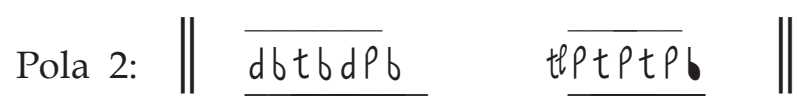
peralihan ke variasi

$$
\rightarrow \overline{d b} \overline{t b} \overline{d P} b \quad \overline{d d} t P \overline{d l}
$$

Kendhangan balungan variasi $\overline{. b} d \overline{\cdot d} d \overline{d d t P b}$

Pola kendhangan jengglengan

$\| . b \quad d \overline{. d} \rho$ tb $d \overline{.} \cdot \bar{d} \quad \dot{b} \|$ peralihan

ke variasi $\rightarrow \cdot \bar{b} d \overline{\cdot d} \rho \overline{d d t} p b$

Kendhangan balungan variasi peralihan ke

jogetan.$b d \overline{\cdot d} d \overline{d d} t p b$

$\rightarrow$ Pola kendhangan jogetan $\|$ PtPt btbt $\|$

jengglengan $\rightarrow\|.6 d \overline{. d} \underline{\rho} \underline{t b} d \overline{. d} b \cdot\|$

Masuk kendhangan vokal

$$
\begin{aligned}
& b \quad \overline{\rho p} \overline{l p} t \\
& \|\underline{. b . b} \underline{. . p \overline{l p} t} \underline{. b . d} \underline{p t \rho b}\|
\end{aligned}
$$$$
\text { jengglengan }\|\overline{. b} d \overline{\cdot d} p \overline{t b} d \overline{\cdot d} b \circ\|
$$$$
\text { kendhangan klotekan }\|\overline{d b} \overline{t P} \overline{d P} b\| \rightarrow
$$

vokal atau bowo

kendhangan gangsaran $d t d t \quad b d P b$ à

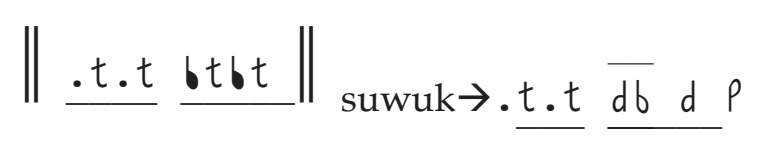

2. Bawa dan vokal pada Penthul Melikan

\section{Vokal 1.}

$\begin{array}{llllllll}\dot{3} & \dot{3} & \dot{2} & \dot{1} & \dot{3} & \dot{2} & \dot{1} & 6\end{array}$

$i$ - ki pen-thul-é me-lik-an

$\overline{.} \begin{array}{llllllll}\dot{1} & \dot{2} & 6 & 5 & 3 & 5 & 2 & 3\end{array}$

ra-mé ra-mé je-jo-gèd-an

$\begin{array}{llllllll}.3 & 5 & 6 & 5 & 3 & 5 & 3 & 3\end{array}$

$i$-reng $i$-reng je-jo-gèd-an

$\begin{array}{llllllll}.6 & i & 2 & i & 6 & i & 6 & 6\end{array}$

mu-ji syu-kur ing pa-ngé-ran

Terjemahan:

Ini tari Penthul Melikan

Bersama-sama menari Hitam-hitam bergembira

Bersyukur kepada Sang Pencipta

Vokal 2.

$\begin{array}{llllllll}\dot{3} & \dot{3} & \dot{2} & \dot{1} & \dot{3} & \dot{2} & \dot{1} & \text { (6) }\end{array}$

Sa-yuk-ru - kun-wis-nya-wi-ji

$\overline{. \dot{1}} \quad \dot{2} \quad 6 \quad 5 \quad 3 \quad 3 \quad 5 \quad 3$

$n g u-m a n-d a n g-w i-w i t-p a-k a r-t i$

$\begin{array}{llllllll}.3 & 5 & 6 & 5 & 3 & 5 & 3 & 3\end{array}$

$s a-m u-b a-r a n g-d e ́ n-p e-p e r-t i$

$\begin{array}{llllllll}.6 & \text { i } & \dot{2} & \mathrm{i} & 6 & \mathrm{i} & 6 & 6\end{array}$

$A-j a-n g a n-t i-n g u-c i-w a-n i$ 
Artinya:

Kerukunan sudah menjadi satu atau sudah terbentuk, Dibunyikan atau disuarakan mulai bekerja, Semua sudah dipelajari, Jangan sampai mengecewakan

Vokal 3. Bawa atau tembang

$$
\begin{aligned}
& \begin{array}{lllll}
6 i \dot{1} & \overline{2} & \overline{22} & 2 & \underline{2 z}
\end{array} \\
& \text { Gus - ti - a - duh-gus - ti } \\
& .6 \quad 3 \quad 56 \quad 6,22 \quad 2 \quad 2 \quad 3 \quad 32 \\
& \text { ing - kang - we - las , u -gi ma - ha a -gung }
\end{aligned}
$$$$
\begin{array}{lllllll}
1 & 2 & 3 & 2 & 2 & 33 & 2
\end{array}
$$$$
\mathrm{Mu} \text { - gi - pa - ring - ka - we - las }
$$

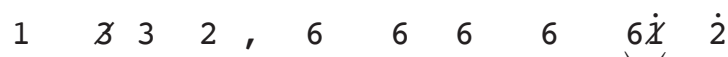

Mring -ka wu la , ar - sa - ba - gas - wa - ka

Terjemahan:

Ya Tuhan, Yang penuh kasih sayang dan maha agung Semoga memberi perlindungan,

Untuk kami, dan semoga diberi kesehatan

\section{Pertunjukan Kesenian Ganongan Melikan}

Pada dasarnya tempat pementasan kesenian Ganongan Melikan di tempat terbuka, seperti lapangan, dan pendapa. Pada perkembangannya, pertunjukan kesenian Ganongan Melikan dipentaskan dalam acara hiburan yaitu tari untuk mengisi acara hari peringatan kemerdekaan Republik Indonesia, mengisi acara hari jadi Kabupaten Ngawi, mengisi acara-acara iven yang ada di Ngawi, dan dipentaskan di sekolah-sekolah dalam acara perpisahan siswa siswi.

\section{Jalan Sajian kesenian Ganongan Melikan}

Pada pertunjukan kesenian Penthul Melikan berbeda dengan jalan sajan pada kesenian Ganongan Melikan, pada dasarnya kesenian Penthul Melikan pengulangan pola yang sama, berbeda dengan Ganongan Melikan lebih terstruktur. Berikut struktur jalan sajian pada musik Ganongan Melikan.
Buka kendang dengan diselehi semua instrumen dengan nada $2 \rightarrow$

buka saron seleh $2 \rightarrow$ buka bonang seleh $6 \rightarrow$ gangsaran $6(2356) \rightarrow$ variasi $1 x$

$\rightarrow$ jengglengan nada 6 àvariasi $\rightarrow$ gangsaran 6 (2356) $\rightarrow$ jengglengan nada $6 \rightarrow$ gangsaran 6 (2356) $\rightarrow$ masuk vokal $\rightarrow$ jengglengan nada 6 $\rightarrow$ gangsaran 6 (2356) $\rightarrow$ tabuhan klotekan $\rightarrow$ gangsaran 6 (2356) $\rightarrow$ masuk bawa atau nembang $\rightarrow$ gangsaran 6 (2356) $\rightarrow$ suwuk gropak.

\section{Kesimpulan}

Kesenian rakyat yang tumbuh dan berkembang dilingkungan masyarakat sedikit banyak akan terpengaruh dengan kehidupan sosial masyarakat setempat. Seiring dengan perkembangan zaman selera dan minat masyarakat ikut berubah. Seperti yang terjadi pada salah satu kesenian yang ada di Ngawi yaitu kesenian Penthul Melikan. Kesenian Penthul Melikan berasal dari dusun Melikan desa Tempuran Kecamatan Paron Kabupaten Ngawi. Kesenian ini diciptakan pada tahun 1952. Sekitar tahun 1980-an kesenian ini mulai vakum, kemudian salah satu seniman yang berasal dari Ngawi bernama Imam Joko Sulistyo mereaktualisasi kesenian Penthul Melikan. Pada tahun 2012 kesenian Penthul Melikan direaktualisasi oleh Imam Joko Sulistyo. Alat musik yang semula sederhana dan apa adanya seperti bedhug, jer, kendhang, peluit dan dua pencon bonang. Imam joko sulistyo menambahkan beberapa alat musik dengan gamelan berlaras slendro, dengan alat kendhang, bonang, kempul, demung, saron, dan menambahkan vokal kemudian kesenian ini diberi nama kesenian Ganongan Melikan.

Dalam mereaktualisasi musik kesenian Penthul Melikan, Imam menerapkan unsur-unsur materi garap, penggarap, sarana garap, perabot garap atau piranti garap, penentu garap dan pertimbangan garap. Sekitar tahun 2014 Kesenian Penthul Melikan kembali dikenal masyarakat dan menjadi salah satu kesenian yang diunggulkan di Kabupaten Ngawi. 
Penyebab terjadinya reaktulaisasi kesenian Penthul Melikan di Kabupaten Ngawi karena beberapa faktor yaitu faktor internal seperti faktor kejenuhan pada seniman, faktor kreativitas pada seniman, dan faktor adanya fasilitas yang memadai, dan faktor eksternal yaitu faktor Faktor kemajuan teknologi informasi dan komunikasi, faktor pengaruh kebudayaan daerah lain dan faktor pendidikan.

\section{Kepustakaan}

Aizid, Rizem. 2015. Islam Abangan Dan Kehidupannya. Yogyakarta: Dipta

Andani, Sri Maryati. 2018. “Tinjauan Garap Gerak Tari Penthul Melikan di Dusun Melikan Desa Tempuran Kecamatan Paron Kabupaten Ngawi". Surakarta: Institut Seni Indonesia Surakarta.

Armis. 1991. "Studi Tentang Perubahan Bentuk Sajian Kesenian Tonggau Di Kecamatan Kuantan Mudik, Kabupaten Indragiri Hulu Provinsi Riau". Surakarta: Sekolah Tinggi Seni Indonesia Surakarta.

Cassirer, Ernst, 1987. Manusia dan Kebudayaan, Jakarta: PT Gramedia. Geertz, Clifford. 1983. Abangan, Santri, Priyayi Dalam Masyarakat Jawa. Pustaka Jaya.

Geriya, I Wayan. 2000. Transformasi Kebudayaan Bali Abad XXI/ 1, Denpasar: Dinas Kebudayaan Provinsi Bali.

Haryanti, Tri. 1999. “Keberadaan Tari Penthul Melikan di Dusun Melikan Desa Tempuran Kecamatan Paron Kabupaten Ngawi". Yogjakarta: Universitas Negeri Yogyakarta.

Martopengrawit. 1975. Pengetahuan Karawitan Jilid A. Surakarta: ASKI. Maryono. 2015. Analisa tari Surakarta. Surakata. ISI Press.

Mulder, Niels. 2001. Mistisme Jawa ideologi di Indonesia. Yogjakarta: PT Lkis. Munandar, Utami. 2014. Kreativitas \& Keberbakatan Strategi Mewujudkan Potensi Kreatif \& Bakat. Jakarta. PT Gramedia Pustaka
Utama.

Pudi, Joike. 2010. "Perubahan Musik Bia di Kabupaten Minahasa Utara". Surakarta: Institut Seni Indonesia Surakarta.

Rohendi, tjejep. 2000. Kesenian dalam Pendekatan Kebudayaan, Bandung: Accent Graphic Communication.

Rori, Olivia Jolanda. 2010. "Perubahan Bentuk Tari Mahamba di Kota Manado". Surakarta: Institut Seni Indonesia Surakarta.

Sahid, Nur. 2000. Interkulturalisme (dalam) T.e.a.t.e.r. Yogyakarta : Yayasan untuk Indonesia.

Sanderson, Stephen K. 1995. Makro Sosiologi Sebuah Pendekatan Terhadap Realitas Sosial, Jakarta: PT Raja Grafindo Persada.

Sari, Yoga Purnama. 2013. "Reog Ponorogo Sebuah Tinjauan Musikal".Surakarta: Institut Seni Indonesia Surakarta.

Soedarsono. 1999. Seni Pertunjukan Indonesia Di Era Globalisasi, Jakarta : Direktorat Jenderal Pendidikan Tinggi Departemen Pendidikan dan Kebudayaan.

Soemardjan. 1981. Perubahan Sosial Di Yogyakarta, Yogyakarta: Gadjah Mada University press.

Sujarno, Dkk. 2003. Seni pertunjukan tradisional, Nilai, fungsi, dan tantangannya, Yogyakarta: kementrian kebudayaan dan Pariwisata, Deputi Bidang Pelestarian dan Pengembangan Kebudayaan, Balai sajian sejarah dan nilai Tradisional Yogyakarta, Proyek Pemanfaatan Kebudayaan Daerah, Daerah Istimewa Yogyakarta.

\section{WEBTOGRAFI}

https:// www.youtube.com / watch?v=VYuqWkFkN_I. Diakses tanggal 11 Februari 2018.

http:/ / eprints.uny.ac.id/20157/1/ SKRIPSI\%20OKTARIA\%20K.W_10209 244009. pdf. Diakses tanggal mengunduh 25 April 2018.

https://id.m.wikipedia.org.Diakses tanggal 21 Juli 2018 